\title{
POVOAMENTO DO BRASIL NO SÉCULO XVIII
}

Tema desta relevância nāo pode, infelizmente, ser adeqüadamente tratado em tão breve comunicação.

Sua importância decorre do fato de que, no século XVIII, ficou definitivamente concretizado o domínio da terra brasileira perlustrada pelas explorações e bandeiras do século anterior, e aceito oficialmente, pelas monarquias espanhola e portuguêsa, o princípio do uti possidetis, reconhecendo-se assim, de jure, no direito internacional, a validade da ocupaçāo anterior de facto.

Podem ser destacadas, entre várias outras, duas causas principais que afetaram o povoamento nesse periodo, salientadas aliás com maestria por Capistrano de Abreu desde 1882 (1). Essas causas, que grosso modo teem influência predominante respectivamente na primeira e na segunda metade do século, sāo a descoberta das minas e a consolidação do sistema colonial.

Aquela, cujos efeitos se fazem sentir ao alvorecer do século - as primeiras jazidas auriferas importantes foram descobertas em 1699 - promoveu, como sempre vem ocorrendo em casos análogos, um verdadeiro rush, que acarretou o deslocamento de apreciáveis massas populacionais para a regiāo da mineraçāo, provocando, pelo poderoso incentivo da auri sacra fames, o povoamento, em caráter permanente, de uma série de regiões do Brasil, e deslocando muito mais para o interior a fronteira demográfica das zonas, principalmente costeiras ou ribeirinhas, efetivamente ocupadas até entāo. Esta causa eficiente atingiu seu apogeu durante o reinado de $D$. Joāo $V$, quando foram fundados, por êsse motivo, a maior parte dos núcleos populacionais da regiāo de Minas $\mathrm{Ge}$ rais, de Goiaz e mesmo de Mato Grosso.

Com o advento de D. José, o gênio político dè seu grande ministro e a conclusāo, meses antes, do Tratado de Madri, cujas negociações foram superiormente conduzidas por Alexandre de Gusmăo, a ênfase quanto ao povoamento do Brasil transferiu-se do campo econômico para o político. A consolidação da linha lindeira, ao Norte, e as guerras pela Colonia do Sacramento, ao Sul, exigiram providencias governamentais relacionadas com o povoamen-

(1). - In Pōrto Seguro, História Geral do Brasil, 3." ed., III, p. 440. 
to. Dêsse periodo, e a título de exemplo apenas, pois nada é possivel desenvolver no limitado espaço disponivel, datam a construçāo dos fortes limitrofes, como o do Principe da Beira, no extremo. oeste do território, e a intensificação do povoamento pela política dita "de casais", especialmente ilhéos, na bacia Amazônica e na Capitania de S. Pedro. E, em tôda sua plenitude, o movimento da consolidaçāo do regime colonial, nos seus aspectos político, militar, econômico e administrativo, e que continuaria até 1808 .

A melhor forma de apresentar sintèticamente os fatos do povoamento no século XVIII parece ser a de estabelecer a comparaçāo visual entre cartas, satisfatórias, elaboradas em princípios e em fins do século. Tal, entretanto, só é possivel em relaçāo a estas últimas, consubstanciadas no mapa de 1798, de que juntamos cópia fotostática, e cujo original pertence ao Serviço Geográfico do Exército Brasileiro.

No que diz respeito à cartografia de fins do século XVII ou principios do XVIII, entretanto, nāo conhecemos exemplares de cartas, mesmo parciais, adeqüadas para os fins em vista. $O$ único bastante merecedor de confiança para ser utilizado é o mapa de Samuel Fritz, de 1691 (2), mas que infelizmente só se refere à regiāo amazônica; os outros que, na mesma época, configuram o restante do Brasil, como o de Coronelli, em 1688 (3), sāo baseados em dados anteriores. Essencialmente, a posiçāo é a seguinte: os últimos bons exemplos de cartografia brasileira são os efetuados na época dos holandeses, até 1654; os restantes, elaborados até fins do século XVII, mormente os da cartografia francesa e italiana, que inclui os pouco fidedignos aparecidos, em 1698, na Istoria delle guerre del regno del Brasile (4) e ainda o de Del Isle (1690) (5), pelo menos os que existem no Brasil, dêles se derivam, ou de elementos ainda mais antigos. $E$, assim sendo, não representam a realidade da ocupaçāo do território brasileiro ao alvorecer do século XVIII. Isto indica uma linha interessante para: a pesquisa, pois até Jaime Cortesão (6), com sua incontestável autoridade, mostra que os mapas básicos para o Tratado de Madrí

(2). - In Atlas IRio Branco, VI, ns. 86a/b, Ministério das Relaçōes Exteriores, Rio de Janeiro.

(3). - "America Meridionale... s.l.n.d." (Veneza, Jiss). Repr. in Le Masson du Parc, Collection of Maps, 2 vols., s.l., 1717. Ministério das Relacōes Exteriores. Rio de Janeiro.

(4). - In Gio: Gioseppe di $\mathrm{S}$. Teresa, Istoria delle gucrre del regno del Brasile..... Roma, 1698, pp. 24/25.

(5). - "Carto do la Terre Ferma du Perou, du brisil et du Pays des Amazones, Dresse sur les Descriptions de Herrera de laet et des PP. d'Acuña et M. Rodrignes... par Guillaume Del Isle..." (1690?), Amsterdão, s.d.. Repr. in Atlas geographique \& universel, avec la gégraphie ancienno moderne.... París, 1700-1762.

(6). - In Brasil: Ministério das Relações Exteriores, Apontamentos das Aulas do Curso de Historia da Cartografia, Geografia, das Fronteiras do Brasil e Mapoteconomia... Rio de Janeiro, 1945, Vol. I, n. 26, III = "O Mapa das Cortes e as razōes dos espanhóis", p. 5 (Mimeografado). 
sāo posteriores a 1730, dos quais um, o de Gomes Freire, é hoje considerado perdido.

Destarte, somos obrigados a suprir tais deficiências por uma descriçāo geográfica aproximada, que tentaremos sintetizar abaixo, distinguindo ainda entre povoamento espanhol e português e entre os limites do Brasil de entāo, que incluia o território do atual Uruguai (a Colônia do Sacramento mudou de dono várias vêzes durante o século XVIII) e o de hoje.

Por volta de 1700 , a situaçāo das regiões permanentemente ocupadas era a seguinte. Com povoamento espanhol, menos importante, apenas dois pontos: o rio Solimões, com aldeiamentos de jesuitas castelhanos, e o núcleo jesuítico dos Sete Povos das Missões, margeando o Uruguai, nas proximidades de S. Borja. Já nāo mais existia o centro populacional de Guairá, destruido pelos paulistas, numa série de incursões predatórias, em meiados do século XVII.

O povoamento português assim se distribuia. Na bacia amazônica, Belém e, ao longo do Amazonas, pequenos núcleos missionários ou militares que seriam origem de Gurupá, Santarém, Óbidos e Mianaus. Povoado pelos carmelitas, o vale do rio Negro até às cachoeiras; penetrado, sem ocupação permanente, o vale do rio Branco; aldeias jesuiticas no vale do Madeira, inclusive as primitivas localizações de Borba (= Trocano) e Itacoatiara. Cametá era o ponto extremo de ocupaçāo no vale do Tocantins.

No Maranhāo existiam, no litoral, Caeté (= Bragança), Tapuitapera e S. Luiz, havendo ocupação dos vales do Mearim e do Itapicurú. No Piaui, aldeias jesuiticas esparsas, no interior sul, em contacto com a Bahia. Ocupados estavam, no Ceará, Camocim, Fortaleza, o vale do Jaguaribe e a zona do Cariri; no Rio Grande do Norte, Natal, 3 Reis Magos, registrando-se considerável expansāo de gado para o interior, em fazendas dispersas. A Paraíba figura com Cabedêlo, Paraiba, às margens do rio dêsse nome e penetraçāo dirigindo-se à serra da Borborema.

Pernambuco, centro dos mais antigos, tinha povoados Itamaracá, Igarassú, Recife, Olinda, Penedo e o atual estado de Alagoas, com ocupaçāo, por engenhos, de todos os pequenos rios; fazendas de criar ocupavam as duas margens do S. Francisco, até além de Paulo Afonso. Sergipe estava, a bem dizer, cheio; S. Cristovāo era o maior centro demográfico, e tanto fazendas de criar como engenhos de açúcar se estendiam até além do rio Real.

$\mathrm{Na}$ Bahia, achavam-se ocupados o litoral norte, o Recôncavo (regiāo mais povoada do Brasil de então), com suas várias cidades e freguesias. Ainda ocupada estava tôda a zona da caatinga, com fazendas de criár, preenchendo o vácuo existente entre o litoral e o sertāo, ao tempo das guerras holandesas. Também ocupado estava o vale do S. Francisco, ininterruptamente, desde sua foz 
até à altura de Pirapora atual (7); penetrados e ocupados, os vales de vários de seus rios, o Paraguaçú até Lençois (8), as cabeceiras dos rios das Contas e Pardo, até o rio Doce; e pela costa, os centros de Camamú, Ilhéos, Pôrto Seguro e Caravelas. O Espirito Santo, além de Vitória, Conceiçāo, S. Mateus e Santa Cruz, tôdas do século XVI, só tinha colonizado o rio Mucutí e a zona entre êste e o Peruipe (9).

No Rio de Janeiro, existiam S. Joāo da Barra, Cabo Frio, Macaé, S. Lourenço (= Niteroi), a cidade do Rio de Janeiro, $\mathrm{Pa}$ ratí, Angra dos Reis e Mangaratiba, na costa; no interior, o recôncavo da baía de Guanabara, Maricá, Inhomirim, Itaborai e Campos. Ocupado estava o baixo curso do rio Paraiba, vazio o médio; povoado esparsamente o caminho para S. Paulo, por onde passa hoje a Estrada de Ferro Central do Brasil, e a regiāo serrana do vale do Paquequer.

Ubatuba, S. Sebastiāo, Santos e S. Vicente, Itanhaen, Iguape e Cananéia, pontilhavam demogràficamente o litoral de São Paulo; no interior havia S. Paulo, Itú, Sorocaba, Parnaiba, Jundiaí, e um rosário de vilas ao longo do vale do alto Paraiba, de Guaratinguetá a Mogi das Cruzes. No Paraná, Paranaguá e Curitiba, por onde passava o caminho de Sorocaba até à Colônia do Sacramento. Em Santa Catarina, existiam S. Francisco do Sul, Ilha de Santa Catarina (= Florianópolis), e Laguna, de onde partia o caminho para os campos do Rio Grande do Sul até à Colônia do Sacramento. Havia gado disperso no atual Rio Grande do Sul, e povoada estava a Colônia do Sacramento. Vasios, e pràticamente desconhecidos: Minas Gerais, Goiaz e Mato Grosso.

Tal era o Brasil de 1700. Um século após, sua extensāo povoada é visivel no mapa da autoria de Antonio Pires da Silva Pontes Leme, datado de 1798 e que até o presente momento, ao que saibamos, nāo foi ainda publicado. Como se vê, o Brasil se expandira imensamente.

Quais os caminhos seguidos pelo povoamento e sua evoluçāo? Estudaram-nos Capistrano de Abreu (10), Felisbello Freire (11) e Raja Gabaglia (12). Roberto Simonsen (13) e, ràpidamente

\footnotetext{
(7). - In Capistrano de Abreu, Capitulos de História Colonial, Rio de Janeiro. $192 \mathrm{~S}$, p. 159

(8). - Apud Felisbello Freire, Mistóna Territorial do Brasil, Rio de Janeiro, 1906, D. 49 .

(9). - Apud ibid. p. 387 .

(10). - Caminhos Antigos e Povoumento do Jrasil, Rio de Janeiro, 1930, pp. 53-143.

(11). - Op. cit.

(12). - Fernando António Raja Gabaglia, "As Linhas de Penetração da Civilizaçāo no Brasil", in Revista do Brasil, Ano VI, vol. XVI, n. 61, pp. 4-10. S. Paulo. ianeiro de 1921 .

(13). - Roberto C. Simonsen, "Recursos economicos e movimentos das populações", in Revista Jrasileira de Estatística, Ano $I$, n. 2, pp. 199-228, Rio de Janeiro, abril-junho 1040. (Especialnente os cartogramas).
} 


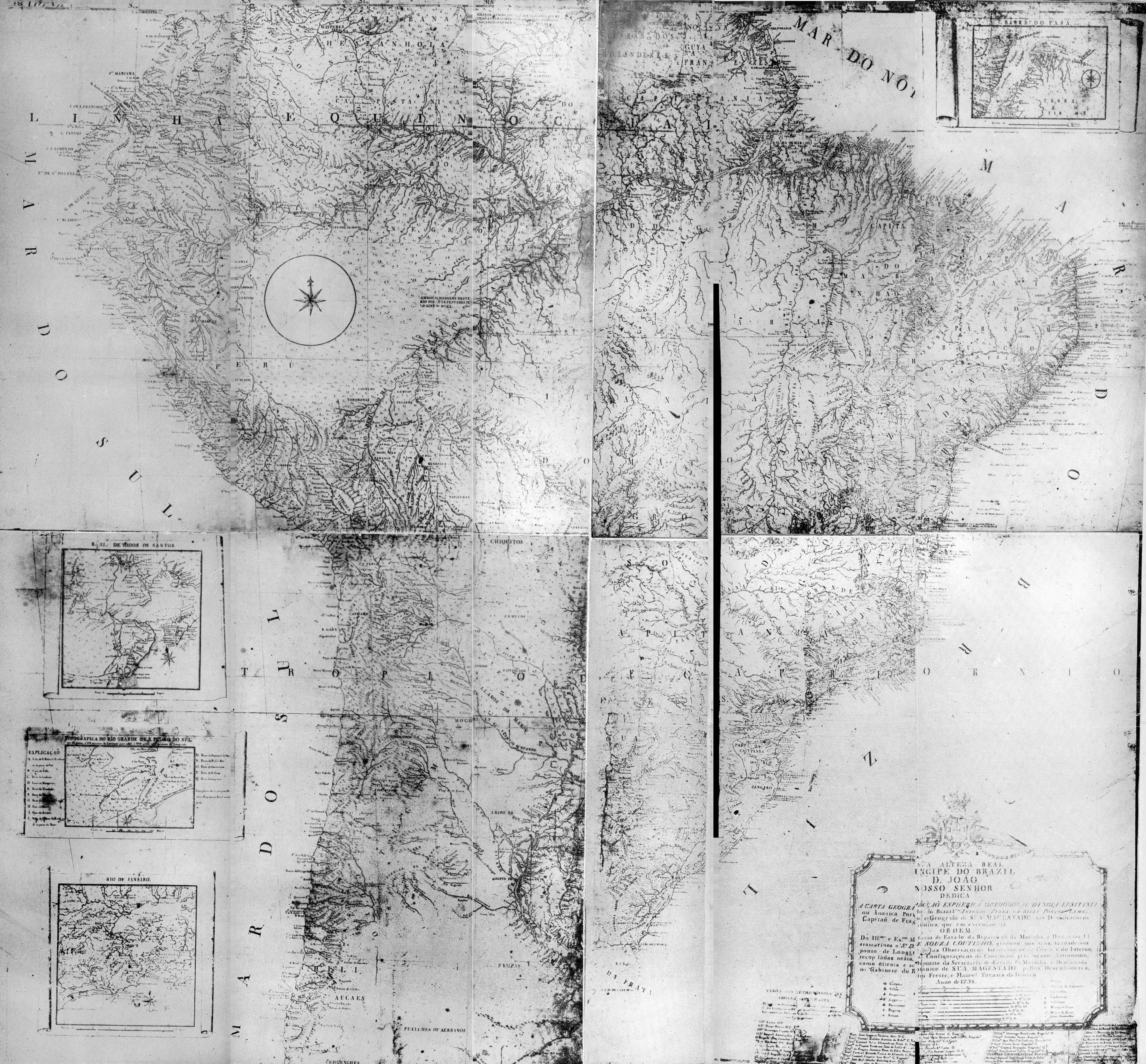


Neiva (14); na Amazônia, especialmente Ferreira Reis (15), Minas Gerais, Cardoso (16). Encontram-se, contudo, elementos esparsos, por vêzes de grande valor, em muitas obras clássicas (17). Como preciosas fontes primárias, temos o trabalho de Antonil (Andreoni) (18), de principios do século XVIII, a ser comparado com os documentos originais de todo o decurso do século, infeliz-

(14). - Artur Hehl Neiva, "Aspectos geográficos da imigração e colonização do Brasil", in Kovista Brasileira de Geografia, Ano IX, n. 2, pp. 93-114, Rio de Janeiro, abril-junho 1947.

(15). - Arthur César Ferreira Reis, História do Amazonas, Manáos, 1931 (especialmente pp. 51-87 e 109-140); e "Casais, Soldados e Degredados na colonisa 'ão da Amasonnia", in Anais do 3.0 Congresso Rio-Grandense de História, Pôrto Alegre. 1940; vol. IV, pp. 2605-2719.

(16). - Manoel da Silveira Soares Cardoso, "Alguns aspectos da vida económica e política do Brasil na primeira década do século XVIrI", in Ocidente, vol. I, n. 2 , Lisboa, junho de $1938_{A}$ pp. 25S-272.

(17). - Por exemplo: Pórto Seguro, op. cit., caps. XXXIX-XLIX; Handelmann, Geschichte von Brasilien, caps. VII-XII, passim, Berlin, 1860; Azevedo Marques, Apontamentos ... da Provincia de S. Paulo ..., Rio de Janeiro, 1879 , especialmente vol. 2, pp. 246-268, passim: Basilio de Magalhães, Expansão georráfica do Brasil colonial, $3 .{ }^{a}$ ed., Rio de Janeiro, 1944, pp. 267-395. Sôbre algumas regiōes isoladamente, cf., entre outros: Guilherme Studart, Datas o Fatos para a História do Ceara, Fortaleza, 1896, I, pp. 120-433, pass.: A. Tavares de Lyra, História do Rio Grando do Norto, Rio de Janeiro, 1921, pp. 281-373, pass.; Felisbello Freire, op. cit., pass., (da maior importancia para a pesquisa, nos estados da Bahia. Sergipe e Espirito Santo): Felicio dos Santos, Memórias do Districto Diamantino, Rio de Janeiro, 1924, (especialmente caps. I, III, IV, XIV e XVI); a monumental História Geral das Bandeiras Paulistas, de Afonso d'E. Taunay, especialmente T. VIII, pp. 555-545, 'Ts. IX e X, S. Paulo, 1946-1949; Pereira da Costa, Em prol da integridade do território de Pernambuco, Recife, 1896; Barbosa Lima Sobrinho, Pernamibuco o São Francisco, Recife, 1929 (especialmente caps. XI-XXVI, pp. 77-168); Ignacio Accioli de Cerqueira e Silva, Memórias llistóricas e Políticas da Provincia da Bahia, 6 vols., Bahia, 1919-1940 (especialmente vols. II, 1925, pp. 142-226, e as preciosas notas de Braz do Amaral, pp. 265-451; e III, 1931, pp. 1-32, e nota 12, pp. 83-84); Luiz dos Santos Vilhena, Recopilasão de Notícias Soteropolitanas o Brasílicus, 2 vols., Bahia, 1921 (especialmente cartas XII-XXIII, vol. 2, pp. 457-907); Mello Mioraes, Chronica Geral do Brazil, 2 vols. Rio de Janeiro, 1886 (especialmente vol. 2, pp. 1-111, passim): Romário Martins, História do Paraná, 2. ed., S. Paulo, 1939 (especialmente caps. VII/VIII, pp. 145-234, e $X / X I$, pp. 281-320); Lucas Alexandre Boiteux, Notus para a Historia Catharinense, Florianópolis, 1912 (especialmente pp. 178-290); Oswaldo R. Cabral, Santa Catharina, São Paulo, 1937 (especialmente pp. 44-106); Carlos Teschauer, Historia do Rio Grando do Sul, 3 vols., Pórto Alegre, 1918-1922, (especialmente os vols. 2 e 3 ); João Borges Fortes, Casaes, Rio de Janeiro, 1932; Aurélio Pôrto, História das Missõos Orientais do Uruguai, vol. I (único publicado), Rio de Janeiro, 1943 (especialmente pp. 155-575); Diogo de Vasconcellos, Historia Antiga de Minas Gerais (1904) e História Media do Minas Gerais (1918), Belo Florizonte, (especialmente a última parte do Liv. I o o Liv. II do primeiro, e todo o segundo); Cardozo, op. cit.; José Martins Pereira de Alencastre, Annaes da Provincia de Goyaz, in Rovista Trim. Inst. Hist. Geog. Bras, Rio de Janeiro, 1864, T. XXVII, Parte Segunda, pp. 5-186 e 230-349: Filippe Jose Nogueira Coelho, Mremorias Chronologieas da Capitania de Matto Grosso... in ibid., T. XIII (1850; 2.2 ed., 1872), pp. 137-199 (vai de 1718 a 1780). Para outras obras de interêsse, cf. Alice Canabrava, "Bandeiras", in Manual Bibliográfico de Estudos Brasileiros, Rio de Janeiro, 1949 , pp. 492-52t;, o melhor existente, embora bastante incompleto ainda. Para mise au point da bibliografia histórica, cf. Brasil, Ministério das Relaçoes Exteriores, Comissão de Estudo dos Textos da História do Brasil, Bibliografia de Historia do Brasil (1044-; ¿́ Easc. publicados até agora).

(18). - André João Antonil (pseud. de João António Andreoni S. J.), Oultura o Opulência do Brasil por suas drogas o minas. Ed. Princeps, Lisboa, 1711: 3.a ed. (a melhor), $\mathrm{S}$. Paulo, 1923, com um estudo bio-bibliográfico de Afonso de E. Taunay. Cf. especialmente pp. 205-272. 
mente disseminados em coleções de publicações (19), sôbre as quais nāo houve, ainda, pesquisa adeqüada e profunda, do gênero da empreendida por Felisbello Freire e que, lastimàvelmente, ficou incompleta, reduzida tāo sòmente à Bahia, Sergipe e Espírito Santo, muito embora haja tentativas locais de ordenaçāo, tal o trabalho de Joāo de Lyra Tavares (20). Esta é uma das principais linhas de pesquisa abertas aos estudiosos, que desejarem preencher uma sensivel lacuna nos estudos brasileiros.

Quais os elementos étnicos, que promoveram êsse impressionante surto de povoamento? Tal é outra linha de pesquisa que se abre, correlatamente à primeira. Ainda aqui, só podem ser dadas por ora respostas genéricas: o português reinol, o negro africano e, de certa forma, o indígena, mas principalmente o verdadeiro sertanejo brasileiro, tanto o mameluco caboclo do nordeste quanto o mulato ou o cafuso de outras regiões, e os que possuiam em vários graus as combinações mais diversas dêsses distintos sangues. Pode-se afirmar que, no século XVIII, se intensificou o tráfico negreiro; falta ainda, nesse capítulo, fazer-se a análise dos documentos originais sôbre a proporçăo dos negros de várias origens importados, traçando a evoluçāo do tráfico em quantidade e qualidade, utilizando, por exemplo, documentos do tipo da carta de Lisboa (21). Apesar das recentes contribuições de Simonsen

(19). - Das quais as principais, numa lista que está longe de ser exaustiva, são: Revista Trimensal do Instituto Histórico o Geografico Brasileiro (1839-; 197 vols. até agora). Rio de Janeiro; Documentos Históricos da Biblioteca Nacional (1928-; 86 vols. até agora) Rio de Janeiro; Anais. da Biblioteca Nacional (1876-; 69 vols,, até agora), Rio de Janeiro; Publicações do Arquivo Nacional (1886-; 39 vols., +1 inumerado, publicados até agora), Rio de Janeiro; Annaes da Biblioteca e Archivo Publico do Pará (1902-1926; 10 vols. publicados), Belém: Anais do Mu'seu Paulista (1922-; 13 vols. publicados até agora), São Paulo; Anais do Arquivo Público da Bahia (1917-; 30 vols, publicados até agora), Salvador; Revista do Instituto do Ceará (1887-; 61 vols. publicados até agora), Fortaleza; Revista do Instituto Arqueológico, Histórico e Geografico Pernambucano (1863-; 41 vols. publicados até agora), Recife; Revista do Instituto Histórico e Geográfico de São Puulo (1895-; 44 vols. publicados até agora), São Paulo; Revista do Instituto Histórico e Geográfico do Rio Grande do Sul (1921-; 27 vols. publicados até agora), Pôrto Alegre; Revista do Instituto Histórico e Geográfico de Mato Grosso (1919-; 60 Tomos publicados até agora), Cuiabá; Revista. do Arquivo Público Mineiro (1896-1938; 25 vols. publicados), Belo Horizonte; Revista do Museu e Arquivo do Rio Grande do sul (1921-1930; 24 ns. publicados), Pôrto Alegre; Revista do Arquivo Municipal de São Paulo (1934-; 132 vols. publicados até agora), São Paulo; Documentos Unteressantes do Arquivo de São Paulo (1895-; 65 vols. publicados até agora), São Paulo; Archivo do Districto Federal (1894-1897; 4 vols. publicados), Rio de Janeiro; Sesmarias - Documentos do Arquivo do Estado de São Paulo (1921-; 5 vols. publicados até agora), São Paulo.

(20). - Apontamentos para a Historia Territorial da Parahyba. Paraíba, 1910-1911 (especialmente vol. 1, pp. 3-488 e vol. 2, pp. 499-502).

(21). - José da Silva Lisboa (futuro Visconde de Cairú), carta escrita em 18:

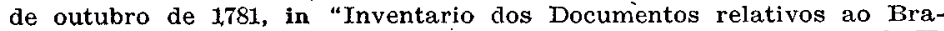
sil, existentes no Archivo de Marinha e Ultramar de Lisboa", vol. II, doc. n. 10.907 (Anais da Biblioteca Nacional do kio de Janeiro, vol. XXXII, Rio de Janeiro, 1914 pp. 494-506, especialnente pp. 504-505.). 
(22) e Goulart (23), ainda năo parece estar definitivamente esclarecida a questāo da quantidade de negros entrados no Brasil durante o periodo do tráfico.

Finalmente, qual o crescimento, em números absolutos, do povoamento brasileiro durante o século XVIII? Como nas outras linhas de pesquisa indicadas, também aqui existe vasto campo de estudos. Contreiras Rodrigues (24), Calógeras (25), Caio Prado Júnior (26), estudaram o assunto, genèricamente; assim Simonsen (27) e Neiva (28). Mortara (29), extrapolando por processos demográficos, admite que em $1770 / 71$ a populaçāo brasileira fôsse de 2.502.000 habitantes, e de 3.660 .000 em 1800/01. Há, entretanto, ampla margem para investigações e correlações nos documentos esparsos da época; exemplo disso é o levantamento eclesiástico mandado fazer na Bahia em fins de $1756 / 57$, publicado por Borges de Barros (30).

Tais são, em suma e a nosso ver, as principais linhas de pesquisa abcrtas aos estudiosos do povoamento do Brasil no século XVIII. Para elucidaçāo de qualquer delas, além dos documentos publicados e utilizados, constantes da bibliografia que apensamos, existe ainda abundante material arquivistico inédito e nāo investigado, localizado, entre nós, nos Arquivos Públicos dos Estados do Pará, Ceará, Pernambuco, Bahia, Rio Grande do Sul, Minas Gerais e Mato Grosso; no Arquivo Nacional no Rio de Janeiro,

(22). - Roberto C. Simonsen, História Economica do Brasil, 155d-1820, 2 Tomos, São Paulo, 1937 (especialmente T.I., cap. VI, pp. 187-217; o cálculo do número de escravos importados ocupa as pp. 201-205).

(23). - Maurício Goulart, Escravidão Africana no Brasil, Das Origens a 1 tingão do Trafico, São Paulo, 1949 (especialmente pp. 125-217). Ainda sobre êsto assunto, ê útil a leitura, alem do livro clássico de Perdigão Malheiro, A Escravidão no Brasil, Rio de Janeiro, 1867 (especialmente, quanto a números de africanos importados, Parte 3.n, pp. 13-14, 48), dos trechos a respeito em Pandiá Calogeras, A Política Exterior do Império, (Rio de Janeiro, 1927, Tomo Especial da Rev. Inst. Hist. Geog. I3ras., I, Cap. IX, pp. 283-332 (especialmente, sobre números, pp. 320-332), e Afonso de $\mathbb{E}$. Taunay, Subsídios para a História do Tráfico Africano no Brasil, São Paulo, 1941 (especialmente caps. XII-XX, pp. 133-229; o exame da questão numérica está nos caps. XXII-XXIII, pp. 235-256)

(24). - F. Contreiras Rodrigues, Tragos da Economia Social e Polftica do brasil Colonial, Rio de Janeiro, 1935, pp. 2S-35 (o crescimento no século XVIII está sumariado às pp. 33-34).

(25). - Loc. clt.

(26). - Formagão do Brasil Contemporáneo, São Paulo, 1942, pp. 29-78.

(27). - Obras citadas, ibid.

(28). - Artur Hehl Neiva, "O Problema Imigratório Brasileiro", in Revista de Imigragão e Colonizadão, Ano $V$, n. 3, pp. 468-591 (especialmente pp. 474-478, 485-486. 493-497; sobre négros, pp. 499-500).

(29). - Giorgio Mortara, "Estudos sôbre a utilizaçāo do censo demográfico para a reconstrução das estatísticas do movimento de população no Brasil. V. Retificação da distribuição por idade da população natural do Brasil, constante dos censos, e cálculos dos óbjtos, dos nascimentos, e das variacões dessa populaçäo no periodo 1S70-1920", in Kevista Brasileira de Estatística, Ano II, n. 5, pp. $39-89$ (o cálculo referido se encontra na Tabela II, Dados retrospectivos sobre a populagão do Brasil, p. 43.).

(30). - F'. Borges de Barros, "Descripção de freguezias creadas nos tempos coloniaes", in Archive Historico, 2.0 vol., Primeira Parte, pp. 25-127, Bahia, 1929. 
e nos Arquivos estadual e municipal de Sāo Paulo; e, em Portugal, no Arquivo Histórico Colonial. Lastimàvelmente, porém, nāo foi esta vasta documentaçāo trabalhada a contento até o presente, nāo só por se achar demasiado dispersa, mas também constituir-se fonte de acesso nem sempre fácil.

Quaisquer estudos realizados nessas direções, aproveitando o material publicado e o inédito, serão da máxima utilidade e importância para os que, interessados no campo das ciências sociais, embora sem a profissāo de historiador, careçam de elementos seguros de natureza histórica para as conclusões a que se alcem no terreno de suas especialidades (31).

ARTUR HEHL NEIVA.

(31). - Nota sôbro o mapa de Silva Pontes reme: - O original dêste mapa encontra-se no Serviço Geográfico do Exército Brasileiro, existindo c6pias antigas em ferro prussiato, tanto na mapoteca do Ministerio das Relações Exteriores, como na da Biblioteca Nacional do Rio de Janeiro. As fotografias do mapa que acompanham êste artigo foram obtidas da cópia existente na Biblioteca Nacional, gracas a nimia gentileza do Dr. José Honbrio Rodrigues, e tècnicamente preparadas pelo Gabinete de Exames Periciais do Departamento Federal de Segurança Pública, cujos recursos técnicos, em pessoal e aparelhamento, foram gentilmente postos a nossa disposicão para essa finalidade. 